\title{
A Lanthanum Picrate Complex of a 1,2-Bisamide Substituted Calix[4]arene.
}

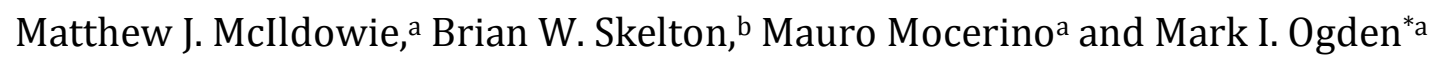

a. Department of Chemistry, Curtin University, Bentley, Western Australia, 6102, Australia.

b. Centre for Microscopy, Characterisation and Analysis, The University of Western Australia, Crawley, Western Australia 6009, Australia

Email: m.ogden@curtin.edu.au

Tel: +6189266 2483

Fax: +61892662300 


\title{
Dedication
}

Dedicated to Professor Jack Harrowfield on the occasion of his $70^{\text {th }}$ birthday.

\begin{abstract}
The synthesis and structural characterization of a lanthanum picrate complex of the proximally-substituted calix[4] arene bisamide, 5,11,17,23-tetra-tert-butyl25,26-bis(diethylcarbamoylmethoxy)-27,28-dihydroxycalix[4]arene (L), is reported. The complex is formulated as $\left.[\mathrm{La}(\mathrm{L}-\mathrm{H}) \text { (picrate) })_{2}\right] \cdot 2.75 \mathrm{CH}_{2} \mathrm{Cl}_{2}$ and crystallises with two inequivalent metal complexes in the unit cell. The differing dispositions of the picrate anions in the two complexes suggest that intramolecular interactions between the aromatic rings of the picrate and calixarene are less significant than the forces involved in the crystal packing of the complexes.
\end{abstract}

Keywords: Calixarene, Lanthanide, Picrate, Crystal Structure 


\section{Introduction}

Calixarene derivatives have proven to be readily accessible and versatile ligands, and they continue to be of interest as ionophores for ion selective electrodes and metal extraction, platforms for catalytic metal complexes, and "cluster keepers".[1-5] While there are many ways that the calixarene framework can be functionalized, alkylation of the lower (phenolic) rim to introduce additional donor groups is perhaps the most readily accessible option, and many different examples are known. Here, we are interested in the introduction of amide moieties, which provide additional 0-donor atoms particular suitable for "hard" metal cations. We reviewed the literature reporting structurally characterized calixarene-amide complexes in 2005,[6] with complexes of Group I and II, lanthanide, and transition metal cations all having been structurally characterized. Such complexes continue to be reported, most usually where the calixarene ionophore is employed for its functionality. For example, the tetraamide 1, has been used to complex Group I and II cations to produce "naked" iodide anions, enabling the study of halogen bonding driven selfassembly between the anion, diiodoperfluoroalkanes and the calixarene.[7,8] Other reports focus on the fundamental complexation behaviour of tetraamide calixarenes, combining structural studies with thermodynamic and/or computational techniques.[9,10] The use of the amide moiety as a linker has included attaching coordinating[11] or fluorogenic[12] groups to the calixarene, or producing calix[4]azacrowns.[13] An amide/ester binding site has been used to create a redox-active tetrathiafulvalene-calixarene that responds to a cation binding event.[14] Our group has reported on the coordination chemistry of the trisamide 3 with lanthanides,[15] and it's use as the ionophore in lanthanidebased light-emitting polymeric materials.[16,17]
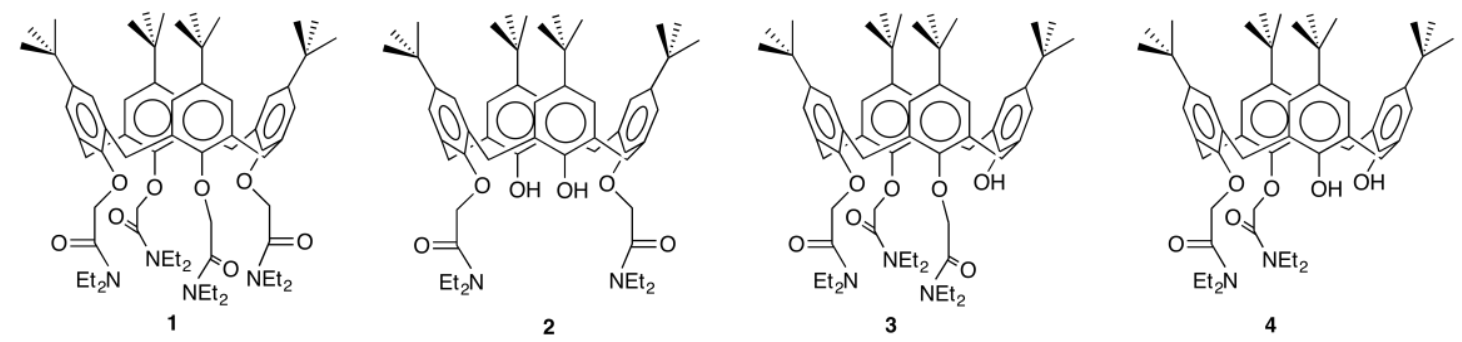
The majority of the calixarene-amide ionophores investigated to date are tetraamides such as 1, or 1,3-bisamides such as 2. 1,2-substitution is much less common, although bisamide 4 has been reported.[18] Structurally characterized metal complexes of proximally substituted calix[4]arenes are limited to the phosphorus-coordinated palladium and nickel complexes of a bisphosphane ligand,[19,20] and a phenol-0 coordinated bismuth complex of the 1,2dibenzylated calix[4]arene.[21] Here we report the synthesis and structural characterization of a lanthanum complex of the bisamide calixarene 4 .

\section{Materials and Methods}

The 1,2-bisamide 4 was isolated as a minor byproduct from the synthesis of the trisamide 2,[22] and gave ${ }^{1} \mathrm{H}$ NMR spectra consistent with the literature report.[18] The lanthanum picrate complex was crystallised as large yellow plates from dichloromethane/acetonitrile, following the procedure used for the lanthanum picrate complex of the partial cone conformer of tetraamide 1. [23]

\section{Crystallography}

Crystallographic data for the structures were collected at 100(2) K on an Oxford Diffraction Gemini diffractometer fitted with Mo K $\alpha$ radiation. Following analytical absorption corrections and solution by direct methods, the structure was refined against $F^{2}$ with full-matrix least-squares using the program SHELXL-97.[24] The picrate ligands of the second molecule were disordered over two sets of sites with occupancies set at 0.5 . As a result of possible close interactions, one methyl group of an ethyl group $(\mathrm{C}(216))$ and oxygen atoms of a nitro group of a picrate anion $(\mathrm{O}(316$, 317)) of molecule 1 and one solvent dichloromethane molecule were also disordered over two sites. Another dichloromethane solvent molecule was refined with occupancy set at 0.5 after trial refinement. The phenolic hydrogen atoms were included at positions consistent with hydrogen bonding interactions and refined with geometries restrained to ideal values. All remaining hydrogen atoms were added at calculated positions and refined by use of a riding model with isotropic displacement parameters based on those of the parent atoms. Anisotropic displacement parameters were employed for all non-hydrogen atoms.

Crystal Data: 
[La(4-H)(picrate) 2$] \cdot 2.75 \mathrm{CH}_{2} \mathrm{Cl}_{2}: \mathrm{C}_{70.75} \mathrm{H}_{86.50} \mathrm{Cl}_{5.5} \mathrm{LaN}_{8} \mathrm{O}_{20} ; M=1702.86$, triclinic, $\mathrm{P}$; $a=12.9700(4), b=22.2552(5), c=27.6046(7) \AA, \alpha=88.039(2), \beta=82.050(2), \gamma$ $=88.378(2)^{\circ}, V=7884.6(4) \AA^{3}, Z=4 ; D_{c}=1.435 \mathrm{~g} \mathrm{~cm}^{-3}, \mu=0.802 \mathrm{~mm}^{-1}$, crystal size $=0.56 \times 0.31 \times 0.045 \mathrm{~mm}^{3} .91432$ reflections collected, 51269 unique $\left(R_{\text {int }}=\right.$ 0.0523), max., min. transmission $=0.965,0.767$. Data $/$ restraints $/$ parameters $=$ $51269 / 428 / 2272 ; \mathrm{GoF}=1.148 . R 1=0.1083(I>2 \sigma(I)), w R 2=0.2593$ (all data). Largest diff. peak and hole $=4.923$ and -1.843 e. $\AA^{-3}$. CCDC 1034162.

\section{Results and Discussion}

Combining lanthanum picrate hydrate with the proximally substituted bisamidecalixarene $\mathbf{4}$ in dichloromethane/acetonitrile resulted in the deposition of large yellow crystals suitable for a single crystal X-ray structure determination. The resulting structure is consistent with the formulation $\left[\mathrm{La}(4-\mathrm{H})(\text { picrate })_{2}\right] \cdot 2.75 \mathrm{CH}_{2} \mathrm{Cl}_{2}$. There are two independent complex molecules present in the structure, and while there is appreciable disorder, the key features of the complex are clear. The two independent molecules are similar, with the La atoms being ten coordinate. The calixarene macrocycle is found in the cone conformation in each molecule, with a dichloromethane solvent molecule situated in the calixarene cavity. The metal coordination sphere of both molecules consists of the four calixarene phenol oxygen atoms, the two amide oxygen atoms and phenolic oxygen atoms and an oxygen atom from a nitro group from the two picrate ligands. In both molecules the coordination of the phenolic oxygen atoms are quite irregular even when considering the substitution pattern of the calixarene. The substituted phenol oxygen lanthanum distances are ; $\mathrm{La}(1)-\mathrm{O}(21)$ 2.961(4), La(1)-O(11) 2.697(4), La(2)$\mathrm{O}(51) 3.005(4), \mathrm{La}(2)-\mathrm{O}(61) 2.787(4) \AA$. . The free phenol oxygen atom distances deviate even more significantly; La(1)-O(31) 2.665(4), La(1)-O(41) 2.208(4), La(2)-O(81) 2.585(4), La(2)-071 2.224(4) A. The residual phenolic protons are thus tentatively assigned to $O(31)$ and $O(81)$ and included accordingly with geometrical restraints. Consistent with this assignment, there are close approaches suggesting a hydrogen bond between these oxygen atoms, and a free nitro oxygen atom of a coordinated picrate in each case; $O(31) \ldots O(316 / 8$ disordered) 2.835(13)/2.641(19), O(81) ...O(716) 2.731(11) A. 
The orientation of one of the picrates ( $41 \mathrm{n}$ ) of molecule 1 is different to those in molecule 2 being oriented to be almost parallel to one of the calixarene $\mathrm{Ph}$ rings (inter-planar angle between the $\mathrm{Ph}$ rings $\mathrm{C}(4 \mathrm{n})$ and $\mathrm{C}(41 \mathrm{n})$ is $15.3(2)^{\circ}$, centroid to centroid $=3.81 \AA$, Figure 1 ). Similarly disposed picrate anions have been observed in the lanthanide complexes of bisamide 2.[25,26] While the significance of aromatic ring interactions in picrate salts has been discussed,[27] the fact that a similar orientation is not observed in molecule 2 suggests the interaction observed here may be a result of "crystal packing forces" rather than a particularly favourable interaction between the aromatic rings. The two picrate anions in molecule 2 are each disordered over two sets of sites, one pair being picrates $(71 n)$ and $(81 n)$ with the other components being labelled (72n) and $(82 n)$. The disorder results in the phenolic oxygen of $(72 n)$ of the second component to coordinate to the $\mathrm{La}(2)$ in approximately the same site as that of the first component but with the nitro oxygen atom bound at the phenolic site of $81 \mathrm{n}$. For $82 \mathrm{n}$, the coordination site of the nitro oxygen atoms are common with $81 \mathrm{n}$ but the phenolic oxygen atoms bound at the site of the nitro group of $71 \mathrm{n}$. The two components of the disordered molecule 2 are shown in Figure 2.

The lanthanum complex structurally characterized here illustrates that the unusual 1,2-substituted bisamide calixarene 4, exhibits similar lanthanide coordination chemistry to the more widely studied 1,3-substituted ligand 2 . More detailed investigations are underway to study the coordination chemistry of this ligand with a broader range of metal cations. 


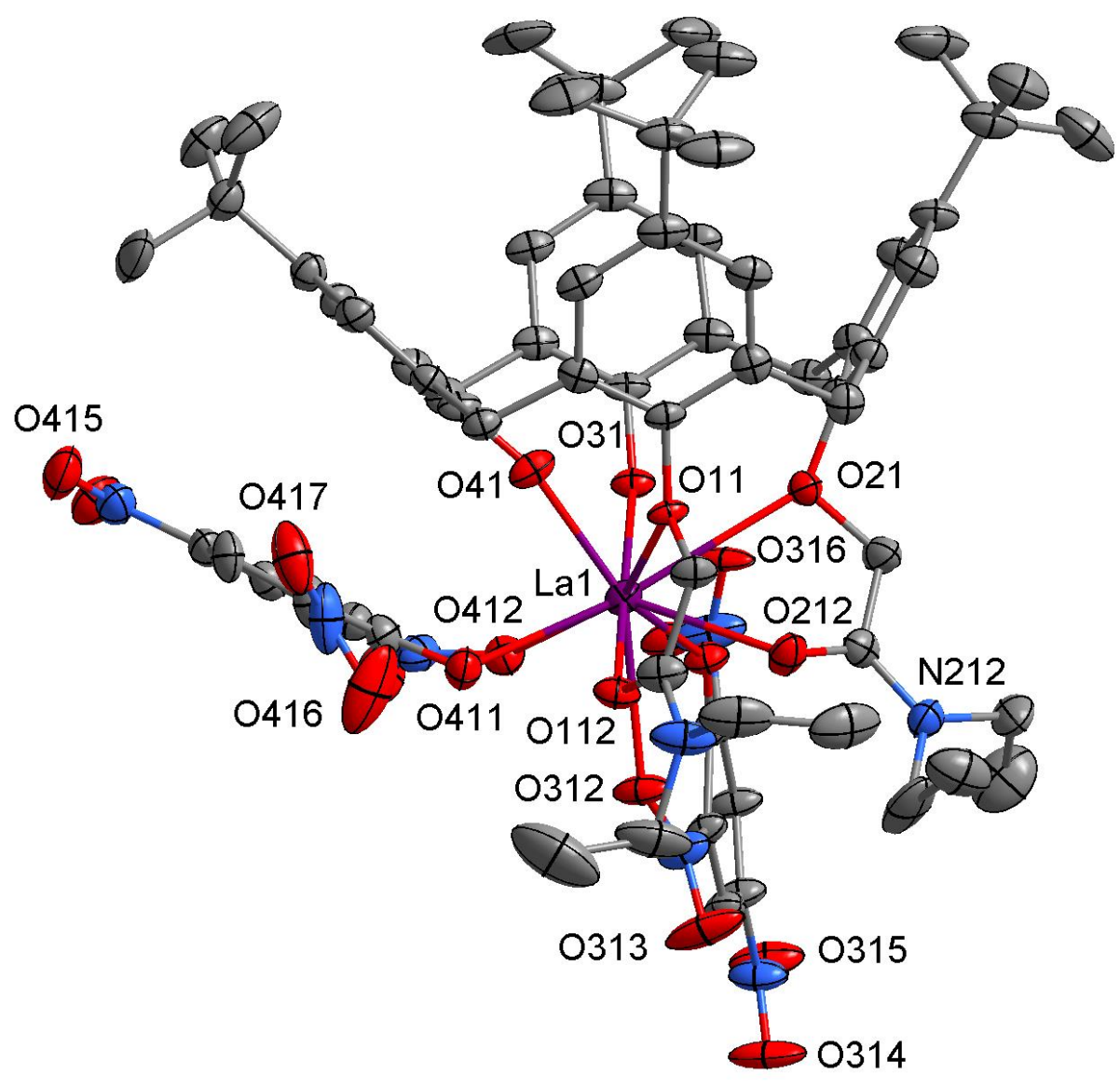

Figure 1. Molecular structure of molecule 1 of $\left[\mathrm{La}(4-\mathrm{H})(\text { picrate })_{2}\right] \cdot 2.75 \mathrm{CH}_{2} \mathrm{Cl}_{2}$. The $\mathrm{CH}_{2} \mathrm{Cl}_{2}$ molecule in the calix, hydrogen atoms and atoms of the disordered components have been omitted
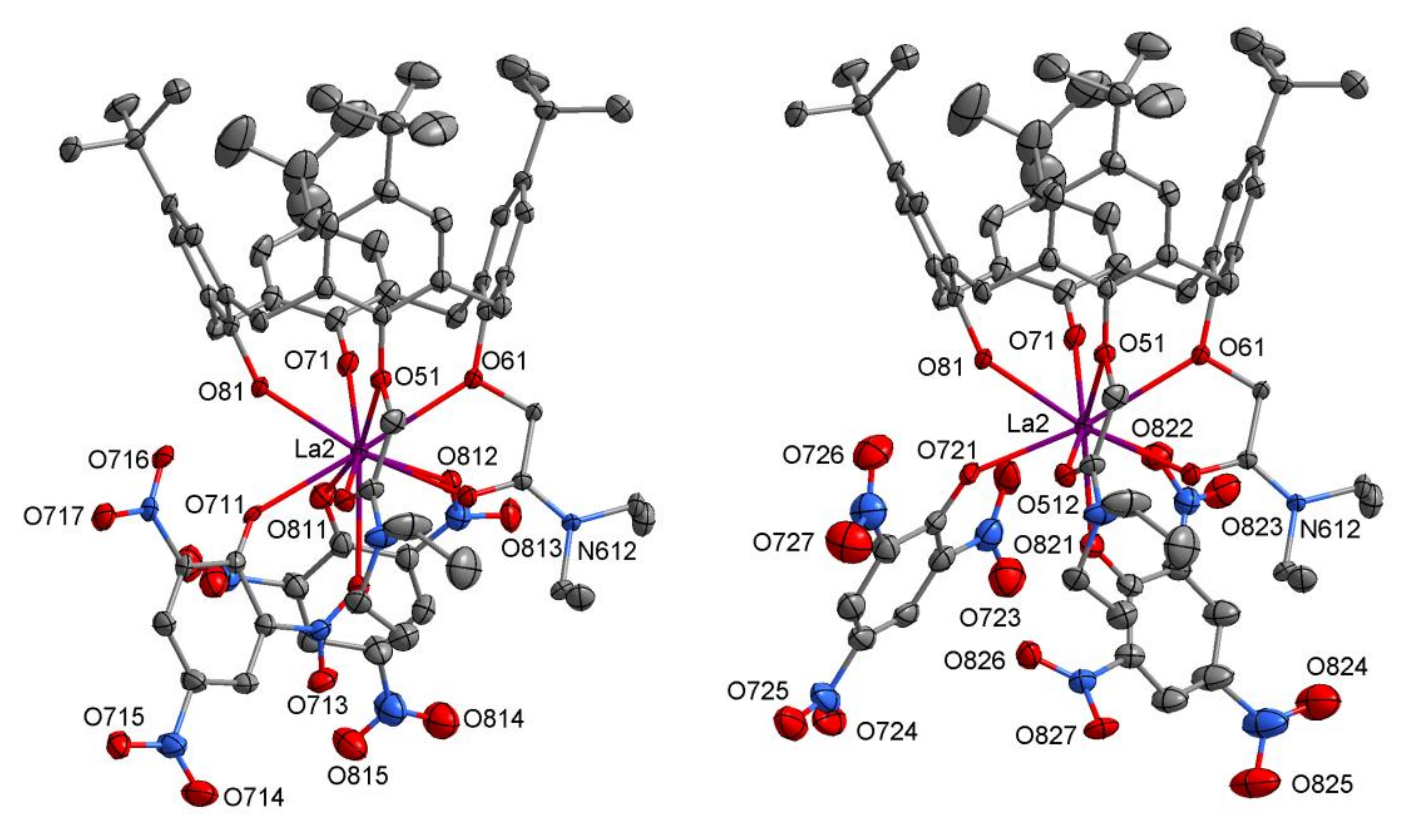

Figure 2. Molecular structure of molecule 2 of $\left.[\mathrm{La}(4-\mathrm{H}) \text { (picrate) })_{2}\right] \cdot 2.75 \mathrm{CH}_{2} \mathrm{Cl}_{2}$ showing the two components of the disordered picrate anions. The $\mathrm{CH}_{2} \mathrm{Cl}_{2}$ molecule in the calix and the hydrogen atoms have been omitted for clarity. 


\section{Acknowledgements}

We acknowledge use of the facilities and scientific and technical assistance of the Australian Microscopy and Microanalysis Research Facility at the Centre for Microscopy, Characterisation, and Analysis, The University of Western Australia, a facility funded by the University, State and Commonwealth Governments.

\section{References}

1. Kumar, R., Lee, Y.O., Bhalla, V., Kumar, M., Kim, J.S.: Recent developments of thiacalixarene based molecular motifs. Chem. Soc. Rev. 43(13), 48244870 (2014).

2. Kim, J.S., Quang, D.T.: Calixarene-derived fluorescent probes. Chem. Rev. 107(9), 3780-3799 (2007).

3. Yang, F.F., Guo, H.Y., Vicens, J.: Mini-review: calixarene liquid crystals. J. Incl. Phenom. Macrocyc. Chem. 80(3-4), 177-186 (2014).

4. Gehin, A., Ferlay, S., Harrowfield, J.M., Fenske, D., Kyritsakas, N., Hosseini, M.W.: Giant Core-Shell Nanospherical Clusters Composed of 32 Co or $32 \mathrm{Ni}$ Atoms Held by 6 p-tert-Butylthiacalix[4] arene Units. Inorg. Chem. 51(9), 5481-5486 (2012).

5. Semeril, D., Matt, D.: Synthesis and catalytic relevance of P(III) and P(V)functionalised calixarenes and resorcinarenes. Coord. Chem. Rev. 279, 5895 (2014).

6. Ogden, M.I., Skelton, B.W., White, A.H.: Synthesis and structural studies of a lanthanide complex of a calix[4]arene tris-amide. C. R. Chim. 8(2), 181187 (2005).

7. Casnati, A., Liantonio, R., Metrangolo, P., Resnati, G., Ungaro, R., Ugozzoli, F.: Molecular and supramolecular homochirality: Enantiopure perfluorocarbon rotamers and halogen-bonded fluorous double helices. Angewandte Chemie-International Edition 45(12), 1915-1918 (2006).

8. Casnati, A., Cavallo, G., Metrangolo, P., Resnati, G., Ugozzoli, F., Ungaro, R.: The Role of Building-Block Metrics in the Halogen-Bonding-Driven SelfAssembly of Calixarenes, Inorganic Salts and Diiodoperfluoroalkanes. Chem. Eur. J. 15(32), 7903-7912 (2009).

9. Horvat, G., Stilinovic, V., Hrenar, T., Kaitner, B., Frkanec, L., Tomisic, V.: An Integrated Approach (Thermodynamic, Structural, and Computational) to the Study of Complexation of Alkali-Metal Cations by a Lower-Rim Calix[4] arene Amide Derivative in Acetonitrile. Inorg. Chem. 51(11), 6264-6278 (2012).

10. Zhou, Y.H., Chen, J., Shang, Y.J., Cheng, Y.: Synthesis, structure and property of three divalent metal complexes of the piperidinoacetyl-containing calix[4] arene. J. Incl. Phenom. Macrocyc. Chem. 74(1-4), 343-351 (2012).

11. Patra, S., Gunupuru, R., Lo, R., Suresh, E., Ganguly, B., Paul, P.: Cation-induced fluorescent excimer emission in calix [4] arene-chemosensors bearing quinoline as a fluorogenic unit: experimental, molecular modeling and crystallographic studies. New J. Chem. 36(4), 988-1002 (2012). 
12. Dinake, P., Prokhorova, P.E., Talanov, V.S., Butcher, R.J., Talanova, G.G.: A new fluorogenic calix[4]arene $\mathrm{N}$-dansylcarboxamide in the cone conformation for selective optical recognition of mercury(II). Tetrahedron Lett. 51(38), 5016-5019 (2010).

13. Bond, A.D., Creaven, B.S., Donlon, D.F., Gernon, T.L., McGinley, J., Toftlund, H.: Metal complexation of calix[4] azacrown derivatives - Evidence for communication between upper and lower functionalised rims. Eur. J. Inorg. Chem.(5), 749-756 (2007).

14. Lyskawa, J., Salle, M., Balandier, J.Y., Le Derf, F., Levillain, E., Allain, M., Viel, P., Palacin, S.: Monitoring the formation of TTF dimers by $\mathrm{Na}^{+}$complexation. Chem. Commun.(21), 2233-2235 (2006).

15. Nealon, G.L., Mocerino, M., Ogden, M.I., Skelton, B.W.: The impact of the lanthanide contraction on the structure of complexes of a calix[4]arene trisamide. J. Incl. Phenom. Macrocyc. Chem. 65(1-2), 25-30 (2009).

16. Ennis, B.W., Muzzioli, S., Reid, B.L., D'Alessio, D.M., Stagni, S., Brown, D.H., Ogden, M.I., Massi, M.: Recyclable calix[4] arene-lanthanoid luminescent hybrid materials with color-tuning and color-switching properties. Dalton Trans. 42(19), 6894-6901 (2013).

17. Driscoll, C.R., Reid, B.L., McIldowie, M.J., Muzzioli, S., Nealon, G.L., Skelton, B.W., Stagni, S., Brown, D.H., Massi, M., Ogden, M.I.: A "plug-and-play" approach to the preparation of transparent luminescent hybrid materials based on poly(methyl methacrylate), a calix[4] arene cross-linking agent, and terbium ions. Chem. Commun. 47(13), 3876-3878 (2011).

18. Bochenska, M., Banach, R., Zielinska, A., Kravtsov, V.C.: Lower rim substituted tert-butyl calix[4]arenes (I). The structure and complexing properties in ion-selective PVC membrane electrodes. J. Incl. Phenom. Macrocyc. Chem. 39(3-4), 219-228 (2001).

19. Dieleman, C.B., Marsol, C., Matt, D., Kyritsakas, N., Harriman, A., Kintzinger, J.P.: Co-ordination chemistry of macrocyclic compounds with dangling phosphines. Unusual NMR shifts in metallo-calix[4]arenes. J. Chem. Soc., Dalton Trans.(23), 4139-4148 (1999).

20. Kuhn, P., Jeunesse, C., Semeril, D., Matt, D., Lutz, P., Welter, R.: Coordination chemistry of large diphosphanes - Directional properties of a calix[4] arene proximally substituted by two $-\mathrm{OCH}_{2} \mathrm{PPh}_{2}$ podand arms. Eur. J. Inorg. Chem.(23), 4602-4607 (2004).

21. Liu, L., Zakharov, L.N., Golen, J.A., Rheingold, A.L., Hanna, T.A.: Synthesis and Characterization of Bismuth(III) and Antimony(III) Calixarene Complexes. Inorg. Chem. 47(23), 11143-11153 (2008).

22. Ogden, M.I., Skelton, B.W., White, A.H.: Syntheses, structural studies and solution properties of iron complexes of some amide-substituted calixarenes. J. Chem. Soc., Dalton Trans.(20), 3073-3077 (2001).

23. Beer, P.D., Drew, M.G.B., Ogden, M.I.: First- and second-sphere co-ordination of a lanthanum cation by a calix[4] arene tetraamide in the partial-cone conformation. J. Chem. Soc., Dalton Trans.(9), 1489-1491 (1997).

24. Sheldrick, G.M.: A short history of SHELX. Acta Crystallogr. A 64, 112-122 (2008).

25. Beer, P.D., Drew, M.G.B., Grieve, A., Ogden, M.I.: Lanthanide Picrate Complexes and Picric Acid Adduct of a Calix[4]Arene Diamide - Syntheses and Structures of [Tm(LH(-2))a], [Ce( $\left.\mathrm{LH}(-2))(\mathrm{MeOH})_{2} \mathrm{~A}\right] \cdot \mathrm{HA},\left[\mathrm{PrLA}_{3}\right]$ and $\mathrm{L} \cdot 2 \mathrm{HA}$ 
(L=5,11,17,23-Tetra-Tert-Butyl-25,27-Bis(Diethylcarbamoylmethoxy)26,28-Dihydroxycalix[4]Arene, HA=Picric Acid). J. Chem. Soc., Dalton Trans.(21), 3455-3466 (1995).

26. Beer, P.D., Drew, M.G.B., Kan, M., Leeson, P.B., Ogden, M.I., Williams, G.: Lanthanide structures, coordination, and extraction investigations of a 1,3-bis(diethyl amide)-substituted calix[4]arene ligand. Inorg. Chem. 35(8), 2202-2211 (1996).

27. Harrowfield, J.: Pi stacking and the co-ordinate bond: Sometimes conflicting factors in molecular recognition, as revealed in the structures of metal picrates. J. Chem. Soc., Dalton Trans.(15), 3165-3171 (1996). 